\title{
БАЗА ДАННЫХ «ЖИЗНЕННЫЕ ТРАЕКТОРИИ ОФИЦЕРОВ РОССИЙСКОЙ ИМПЕРАТОРСКОЙ АРМИИ В 1914-1922 ГГ.»: ИНФОРМАЦИОННЫЙ ПОТЕНЦИАЛ И ПЕРВЫЕ РЕЗУЛЬТАТЫ ОБРАБОТКИ
}

В статье определены возможности электронной просопографической базы данных для многомерного изучения биографий офицеров российской императорской армии в 1914-1922 гг. Автор сформировал выборку социально-профессиональных данных о 1,5 с лишним тысячах офицеров гарнизонов Воронежской, Курской, Тамбовской губерний на 1914 г. и изменениях их жизни и карьеры на отрезках Первой мировой войны, Революции 1917 г., Гражданской войны. Анализ показателей возрастного, социально-сословного, национально-религиозного, образовательного состава, карьерного движения изученной когорты офицеров на 1914 г. в сравнении с социально-профессиональным обликом всего офицерского корпуса России показал типичность этой когорты, правомерность формулирования по результатам ее анализа широких выводов, положений, обобщений. Первые результаты обработки базы данных свидетельствуют, что по показателю возраста в изученных гарнизонах, как и в армии в целом, преобладали офицеры средних возрастов. В когорте было относительно немного молодых офицеров, но относительно большое число возрастных командиров (свыше 50 лет), которые физически не совсем были готовы к предстоящей войне. Установлено, что сословный состав офицеров гарнизонов Воронежской, Курской, Тамбовской губерний на 1914 г. был типичен по явному преобладанию дворянства. Но все-таки треть данной группы офицеров происходила из других сословий. Автор выявил, что в национально-религиозном отношении около $90 \%$ членов изученной когорты были славянами православного исповедания. Небольшими, но заметными группами являлись поляки-католики и немцы-лютеране. По данным об образовании выяснились типичное для российского офицерского корпуса начала $\mathrm{XX}$ в. примерное равенство выпускников военных и юнкерских училища, близкая к общероссийской доля офицеров, получивших военное академическое образование. Для карьерного продвижения офицеров исследованной выборки, как и всех офицеров мирного времени, было характерно сравнительно замедленное получение званий и наград. Только около 100 офицеров когорты участвовало в русско-турецкой войне 1877-1878 гг, русско-японской войне 1904-1905 гг., других военных кампаниях России конца XIX - начала XX в. Большинству офицеров предстояло набираться боевого опыта в ходе Первой мировой войны.

Ключевые слова: офицерство, просопография, историческая информатика, базы данных.
The article defines the possibilities of electronic prosopographic database for multidimensional study of biographies of officers of the Russian Imperial army in 1914-1922. The author formed a sample of socio-professional data on more than 1.5 thousand officers of the garrisons of Voronezh, Kursk, Tambov provinces in 1914 and changes in their lives and careers during the First World War, the Revolution of 1917 and the Civil war. The analysis of indicators of age, social class, national-religious, educational structure, career movement of the studied cohort of officers for 1914 in comparison with the socio-professional appearance of the entire Russian officer corps, has shown the typical character of this cohort, the legitimacy of formulating broad conclusions, provisions and generalizations based on the results of its analysis. The first results of database processing show that in terms of age in the studied garrisons, as well as in the army as a whole, middle-aged officers predominated. There were relatively few young officers in the cohort, but a relatively large number of age commanders (over 50 years old) who were not physically quite ready for the coming war. It is established that the class composition of officers of the garrisons of the Voronezh, Kursk, Tambov provinces in 1914 was typical of the apparent predominance of the nobility. But still a third of this group of officers came from other estates. The author revealed that about $90 \%$ of the members of the studied cohort were Slavs of the Orthodox confession. Small but notable groups were Catholic poles and Lutheran Germans. According to the data on education it turned out typical for the Russian officer corps of the early $X X$ century approximate equality of graduates of military and cadet schools, close to the all-Russian proportion of officers who received military academic education. For career advancement of officers of the studied sample, as well as all officers of peacetime, was characterized by a relatively slow receipt of ranks and awards. Only about 100 officers of the cohort participated in the Russian-Turkish war of 18771878 , the Russian-Japanese war of 1904-1905, other military campaigns of Russia in the late XIX - early XX century 
most of the officers had to gain combat experience during the First World War.

Историография истории российского офицерства начала XX в. весьма обширна. Однако опубликовано сравнительно немного работ в которых предпринимались попытки многомерного количественного анализа социального облика и жизненного пути представителей офицерского корпуса. Среди классических исследований темы можно отметить монограсфию П. А. Зайончковского, в которой представлены статистические данные о разных сторонах облика офицеров конце XIX - начала XX в. [5]. В современной историографии разнообразные количественные характеристики дореволюционного офицерства представил В. Суряев [13].

С другой стороны, в последние десятилетия российские историки получили возможность изучать массовые источники по истории офицерства периода Первой мировой и Гражданской войн созданные в Советской России и в Русском зарубежье. Особенно отметим специальные Интернет-ресурсы: «RIA 1914.info», «Русская армия в Великой войне», «Militera.lib.ru. Военная литература». На данный момент этот богатейший источниковый материал представляет собой мало систематизированную коллекцию фактов $[2,11,12]$

Наиболее ярким образцом такой коллекции является база данных С. В. Волкова, включающая в себя более 300 тыс. биографических справок о Белой Гвардии [3]. Но этот ценнейший ресурс с точки зрения информатики никак не структурирован и не поддается количественной обработке современными методами. Обсчитать десятки тысяч человек по многим параметрам «карандашиком и палочками» практически невозможно.

Существенное преимущество над таким материалом имеют электронные просопографические базы данных, которые советские историки стали формировать еще в 1970-1980-е гг. для составления обобщенных характеристик определенных групп людей в целях определения путей их социальной мобильности и карьерных устремлений. Уже к началу 2000-х гг. накопился немалый опыт создания электронных просопографий [6]. Этот опыт продолжает накапливаться.

Просопографический метод позволяет создать коллективную (типичную) биографию однородной группы людей и на этой основе заполнять типичными показателями недостаток сведений у отдельных персоналий.

В нашем случае это оказалось чрезвычайно важным, поскольку мы попытались в базе данных систематизировать и провести количественный анализ сотен биографий русских офицеров, чья сравнительно спокойная военная карьера конца XIX - начала XX в., редко прерываемая короткими войнами, закрутилась в вихрях Первой мировой войны, Революции 1917 г., гражданского противостояния в России, стала выписывать разнообразные «траектории» и сопровождалась заметной потерей информации.
Key words: officers, prosopography, historical informatics, databases.

Цель статьи состоит в оценке возможностей использования компьютерных технологий для систематизации и анализа информации о социально-политическом облике определенной когорты офицеров на 1914 г. и их жизненном пути в военно-революционный период 1914-1922 гг

Поскольку когортный анализ предполагает в первую очередь изучение состояние объекта на начальный год исследования, мы посчитали необходимым специально выяснить, как сформировался социальный облик избранной группы офицеров в дореволюционный период и представить в статье первые результаты обработки этого блока базы данных. Исследование судеб представителей когорты на последующих отрезках периода 1914-1922 гг. станет задачей дальнейшего анализа обширной базы данных.

В отличие от «готовой» статистики электронные просопографические базы данных позволяют их создателям самим вычислять статистическими приемами многогранные характеристики большой группы людей.

Мы сорормировали просопографическую базу данных на основе биографий 1156 офицеров, служивших в 1914 г. в гарнизонах Воронежской Курской и Тамбовской губерний. Выбор губерний определялся тем, что здесь располагались сравнительно большие гарнизоны всех родов сухопутных войск, что позволяет сделать типологическую выборку для тщательного анализа более тысячи офицерских биографий. Для нашей темы особенно существенно то, что в годы Гражданской войны, через территории губерний проходили различные фрронты, которые давали офицерам большие, чем в глубоких тылах, возможности выбора между красными, белыми, казаками, украинскими войсками.

С точки зрения социологии - это классическая когорта, группа людей, выделенная по общему признаку, в данном случае по общему месту службы. Поэтому базовым источником стали Адрес-календари служащих соответствующих губерний, которые включали и данные об офицерах, дислоцированных на территории губерний воинских частей. Обычно выделение когорт предполагает дальнейшее изучение их жизненного пути, определение их места в одних и тех же исторических событиях $[1,10]$.

Для понимания «обычных» биографий в «необычное время» мы решили разделить базу данных на 4 блока: довоенный период; 1914-1916 гг.; 1917-1918 гг; 1918-1922 гг. В каждом блоке в зависимости от особенностей конкретного отрезка истории созданы информационные поля о местах службы (гарнизоны, фронты, «лагеря» Гражданской войны, уход в «обыватели»), званиях, должностях, военных судьбах (жив, убит, ранен, плен, пропал без вести) наградах.

Формуляр БД создан на платформе Excel, которая позволяет заложить в одну строку (пусть 
и длинную, но единую) формализованный жизненный путь одного человека. Программа дает достаточные для нашего исследования возможности строить необходимые таблицы, создавать вычисляемые поля.

Проведенный на данный момент анализ показателей 1-го блока позволяет говорить не только об информационных возможностях базы данных, но и о весомости результатов ее обработки для определения общих и особенных черт социально-профессионального портрета избранной когорты офицеров накануне Первой мировой войны.

Показатель даты рождения дает возможность для вычисления сроков продвижения офицеров по службе, а, главное, для выяснения возраста в поворотные моменты жизненной судьбы. Произведенные подсчеты показали типичное для армейских структур распределение офицеров по возрастным группам. Более 80 \% составили люди возраста от 24 до 53 лет. Очень молодые офицеры до 23 лет в наших подсчетах не превысили $4 \%$. Для мирного времени было обычным продолжение службы заметной группы пожилых осицеров (более $13 \%$ ).

Полученные нами результаты можно сопоставить с опубликованными П. А. Зайончковским статистическими сведениями о возрастном составе некоторых групп офицеров. В частности, не выглядит необычным наличие в нашей базе данных офицеров старше 60 лет. Зайончковский приводит сведения о том, что в начале XX в. обычным явлением было наличие бригадных командиров в возрасте 65-72 лет, полковых - 62-63 года [5, c. 193].

Он приводил статистику возрастных групп офрицеров одной из дивизий, в соответствии с которой в этой части состояли офицеры от 19 лет. В нашей выборке оказались даже 17-летние.

Данные об окончании военного училища позволяют вычислить возраст вступления в офицерскую службу. При всем разнообразии правил поступления в российские военные и юнкерские училища минимальный возраст поступления устанавливался в 16 лет. При 2-3 летнем периоде учебы большинство юнкеров могли заканчивать училища до 20 лет. Но, поскольку эти правила разрешали поступать в училища лицам до 24 лет, разброс значений возраста окончания училища был относительно большим [4].

Большинство офицеров нашей когорты (свыше 85 \%) завершали учебу в «нормальные» 1924 года. Слишком молодые выпускники училищ составляли менее 5 \%. «Великовозрастные» выпускники насчитывали 9-10\%.

$49 \%$ нашей выборки окончили военные училища, т.е. имели, скажем так, полноценное среднее военное образование. Чуть более половины получили военное образование в юнкерских училищах. По образному выражению историков А. А. Михайлова и С. А. Филюка, юнкерские училища стали теми воротами, через которые в офицерский корпус проникали выходцы из недворянской среды [10].
В принципе наши данные близки к цифрам об уровне военного образования российских офицеров начала XX в., которые привел П. А. Зайончковский: выпускников военных училищ - 55-60\%, юнкерских $-40-45 \%[5$, с. 170$]$.

Некоторые историки считают, что выпускникам юнкерских училищ, не обладавшим хорошей подготовкой и почти не имевшим шансов на получение высшего военного образования, было трудно сделать хорошую карьеру - потолком для большинства из них была должность ротного командира в пехоте и чин капитана [4, с. 58-59]. В нашей выборке три четверти выпускников юнкерских училищ действительно не поднялись выше звания капитана. Но были и существенные исключения: 3 выпускника таких училищ стали генерал-майорами, около 20 полковниками, более 30 подполковниками. Так что работа с конкретными базами данных показывает в очередной раз необходимость осторожного подхода к любым обобщениям, не основанным на количественных показателях.

Полученные результаты показывают примерное равенство выпускников столичных и провинциальных военных училищ. Воспитанники военных училищ формировались как личности не только в стенах своих учебных заведений. Курсанты столичных училищ имели больше возможностей знать политическую жизнь. Они нередко стояли в караулах во время важных государственных мероприятий, участвовали в столичных парадах. В годы учебы они могли приобщаться к высоким культурным ценностям. Столичная среда создавала условия для формирования важных и полезных в будущем связей в обществе.

Воспитанники провинциальных военных училищ имели больше возможностей знать жизнь простого народа. В будущую военно-революционную эпоху умение общаться с простыми людьми, многие из которых вскоре стали солдатами или активными участниками революционных событий, по-житейски могло оказаться очень важным.

При рассмотрении уровня образования офицеров разных родов войск выясняется, что военные училища окончили $35 \%$ пехотинцев, $99 \%$ -артиллеристов, 51 \% кавалеристов. Первые два показателя практически полностью совпали с общероссийскими данными, приведенными В. Суряевым [13, с. 125]. Процент кавалерийских офицеров - выпускников военных училищ в нашей выборке оказался выше, чем по России в целом.

По данным П. А. Зайончковского, в 1904 г высшее военное образование имели 1232 офицера Генерального штаба (выпускники академий записывались в разряд офицеров Генштаба [5, c. 178]). «Наши» 42 выпускника академий составляли чуть менее $2 \%$ от всех российских офицеров с высшим военным образованием. Это немного меньше доли офицеров выборки во всем российском офицерском корпусе. Такое понятно, если учитывать, что выпускники академий в значительной мере попадали в Генштаб и столичные воинские части, нежели в провинциальные части. 
Большинство офицеров когорты поступало в военные училища и оканчивало их в 1870-е и последующие годы, когда военное образование формально стало всесословным. Но нельзя не учитывать того, что в реальной жизни российского общества, особенно его армейской части вплоть до начала XX в. сохранялось привилегированное положение дворянства. Поэтому мы посчитали важным проанализировать сословное происхождение персоналий конкретной базы данных. Как и следовало ожидать, среди известных по показателю социально-сословного происхождения представителей изучаемой когорты офицеров большинство составили дворяне - свыше $70 \%$. И все-таки наши данные показывают, что в начале XX в. в составе кадрового офицерства могли оказаться представители всех сословий Очевидны сравнительно высокие устремления в офицерскую среду представителей мещанства. Напротив, среди них оказалось сравнительно мало выходцев из крестьян. Единичные факты выбора офицерской карьеры представителями сословий купцов, почетных граждан, духовенства, думается, говорят об экзотичности такого выбора людьми из этих слоев общества.

Изученная группа офицеров гарнизонов Воронежской, Курской, Тамбовской губернии по показателю сословности при сравнении с общероссийскими данными выглядит типичной. По приведенным П. А. Зайончковским данным о сословном составе офицеров российской армии на 1895 г., почти одинаковой оказалась доля дворян (67\%), крестьян (3\%), купцов (2\%), казаков $(0.7 \%)$. В общероссийском офицерском корпусе больше числилось почетных граждан - 5 \% и выходцев из духовенства - $6 \%$, но намного меньше оказалась доля мещан - 7 \% [5, с. 204-205].

Для определения успешности продвижения в чинах мы решили сопоставить достигнутые звания с возрастом офицеров нашей когорты на 1914 г. Мы исходили из того, что в соответствии с правилами производства в обер-офицеры 1900 г получение очередного воинского звания полагалось раз в 4 года. Полагая, что средним возрастом окончания училища и получения чина подпоручика (корнета) был 21 год, мы считаем, что звания поручика типичный осрицер получал примерно в 25 лет, звание штабс-капитана (штабс-ротмистра) в 29 лет, звание капитана (ротмистра) - 33 года Получение званий старших офицеров (подполковника и полковника) и генералов зависело не столько от возраста, сколько от наличия командных должностей. Мы понимаем, что наши расчеты схематичны. Для того, чтобы увидеть эту не типичность, мы выделили тех, кто получал звания слишком рано или слишком поздно.

Полученные результаты в целом отражают характерные для того времени этапы получения очередных чинов. Крайне редкими оказались в базе данные сведения об очень раннем получении званий штабс-капитанов

Теоретически звание полковника невозможно было достичь до 40 лет. В нашей базе самым мо- лодым полковником оказался офицер для поручений при штабе 5-го армейского корпуса в Воронеже Фердинанд Фердинандович Фешот, который получил звание к 39 годам. В 1903 г. он закончил Николаевскую академию Генерального штаба, что, безусловно, повлияло на его карьеру.

Сравнительно немалой оказалась группа офицеров, засидевшихся в воинских званиях. В частности, мы отнесли к засидевшимся 106 из 111 (95\%) капитанов (ротмистров). Некоторые известные в исторической литературе данные подтверждают типичность такой ситуации П. А. Зайончковский привел сведения конца XIX в. - 4452 капитанах армейской пехоты, состоявших в строевых частях, 98\% которых оставались в этом звании после 35 лет. Ссылаясь на наблюдения современников армейской жизни начала XX в., историк приводил средний возраст командиров рот (капитанская должность) - 46 лет [5, с. 188-189]. В. Суряев приводит данные 1903 г. о том, большинство армейских офицеров производились в чин капитана только к 44-45 годам $[13$, с.117]. Наши данные в целом близки к приведенным в литературе общероссийским показателям. Большая часть когорты попала в группу лиц, получавших очередные звания раз в 4-8 лет, т.е. несколько медленнее среднего срока. Заметно меньшее число офицеров поднимались в чинах раз в 1-4 года. В исторической литературе факты замедленного движения офицеров от чина к чину в мирное время отмечаются как обычное явление [5, с. 193-194].

Изучение различий в ходе получения званий в отдельных родах войск показало наибольшую типичность пехотных офицеров. Наиболее заметную специфику в процессе движения воинских званий демонстрирует группа офицеров, служивших в управлениях уездных воинских начальников. В принципе это понятно. На такие военно-чиновничьи должности попадали немолодые офицеры уже в чинах. Конечно, движение в чинах этих офицеров было ограничено в сравнении с молодежью, начинавшей военную карьеру.

Еще одним показателем успешности карьерного движения мы посчитали «скорость» получения наград. При обобщении полученных данных мы исходили из того, что награды офицеры мирного времени получали несколько реже, чем звания Данные о числе награжденных представителей нашей выборки (минимум 200 чел. или $16 \%$ от всей совокупности) представляются достаточно весомыми для офицеров мирного времени. Конечно, сведения о довоенных наградах могли не попасть в их послереволюционные биографии. Но вполне реалистичным может быть предположение о том, что многие офицеры начала XX в. не прошедшие военные кампании и не имевшие большой выслуги, вообще не имели наград.

Среди известных по числу наград наименьшую группу составили те, кто получал их быстрее, чем за 5 лет. Треть награжденных офицеров получила свои ордена в среднем за период 5-10 лет. Но большинство изученной группы офицеров награждалось очень редко - в период свыше 10 лет. 
Поскольку боевые награды всегда были стимулами офицерской службы, несложно предположить, что неизбалованные орденами офицеры тыловых гарнизонов Воронежской, Курской, Тамбовской губерний особо стремились к наградам в годы 1-й Мировой войны.

Подсчеты доли известных награжденных офицерам по разным родам войск показали небольшой разброс показателя (в интервале 10-20\%). Высокой оказалась доля награжденных среди офицеров управлений воинских начальников (более 50 \%). Это лишнее подтверждение того, что на такие военно-чиновные должности назначали опытных и заслуженных офицеров. С другой стороны, сравнительно немалой была доля офицеров-быстрых получателей наград в пехоте и особенно в артиллерии. Главным объяснением в данном случае могут быть факты, связанные с участием офицеров в военных кампаниях конца XIX - начала XX B.

Факты наличия боевого опыта важны для понимания будущих судеб офицеров 1914 г. В нашей базе данных оказалось 17 чел., относительно которых мы знаем об участии в русско-турецкой войне 1877-1878 гг. и русско-японской войне 1904-1905 гг. 10 из них прошли только сражения русско-турецкой войны и, конечно, «подзабыли» запах пороха. В русско-японской войне в общей сложности участвовало 86 чел. Понятно, что участие в этой войне было обретением современного для начала XXв. боевого опыта, безусловно, пригодившегося в Первой мировой войне [8].

255 чел. (22 \%) в силу своего возраста могли бы участвовать в войнах последней трети XIX начала XX в. Но в их подробных биографиях нет данных о боевом опыте. Мы не вправе утверждать, что эти офицеры, находившиеся на службе в период русско-турецкой и русско-японской и других войн того периода, уклонялись от участия в военных действиях. Российская армия располагалась на огромных просторах, часть офицеров могла служить вдали от фронтов. 69 офицеров (6\%), родившихся после 1887 г., «не успели» повоевать по объективным причинам.

В целом большинство изученной когорты офицеров были не обстрелянными воинами. Сражения первой мировой войны стали для них первым боевым опытом.

Мы также решили выяснить роль национально-религиозного фактора офицеров когорты, предполагая, что впоследствии в эпоху войны с Германией и Австро-Венгрией, в революционную эпоху разгула национальных и религиозных предрассудков этот личностный показатель мог иметь существенное значение.

Поскольку в изученных нами биографических материалах оказалось недостаточно прямых сведений о религиозной и тем более национальной принадлежности представителей данной когорты, мы решили определить этот показатель экспертным путем по сочетанию фамилий, имен, отчеств.

Наши экспертные данные во многом совпадают с опубликованными в работах коллег показателями религиозного состава российского офицерства начала XX в.: более 80 \% - православные, 4-13\% - католики, 5-15\% - лютеране $1 \%$ - представители мусульман, грузин, армян, других иноверцев [5, с.196-199; 13, с. 128].

В целом, несмотря на определенную неполноту информации, созданная база данных достаточна для характеристики социально-профессиональных признаков типичной группой российских офицеров начала XX в.

В очередной раз апробирована возможность просопографической базы данных распространять типичные черты персонажей на частично неизвестные признаки остальных фигурантов совокупности.

Главными показателями типичности изученной когорты офицеров стало наличие в ней представителей всех основных родов войск российской армии - пехоты, кавалерии, артиллерии, а также интендантских служб, военно-учебных заведений, воинских присутствий.

Анализ показателей возрастного, социально-сословного, национально-религиозного, образовательного состава, карьерного движения отдельной выборки офицеров позволяет утверждать о значительной тождественности этих показателей соответствующим характеристикам всего офицерского корпуса российской армии кануна Первой мировой войны.

Надеемся, что дальнейшее изучение с помощью инфрормационных технологий биографий когорты офицеров во время мировой войны, революции, гражданской войны позволит сделать выводы, которые уточнят сформировавшиеся в историографии обобщения о судьбах российского офицерства в бурную эпоху 1914-1922 гг

\section{Источники и литература}

1. Блоссфельд Х.-П., Хьюнинк И. Исследование жизненных путей в социальных науках: темы, концепции, методы и проблемы // Журнал социологии и социальной антропологии. 2006. №1 . С.15-45.

2. Военная литература (МИЛИТЕPA) URL: http://militera.lib.ru (Дата обращения 15.08.2019).

3. Волков С. В. База данных №2: “Участники Белого движения в Poсcии» [1995-2016]. URL: http://swolkov.org/2_ baza_beloe_dvizhenie/2_baza_beloe_dvizhenie_abc-01.htm (Дата обращения 08.08.2019).

4. Гребенкин А. Н. Правила приема в военно-учебные заведения Российской империи в 1863-1917 гг. // Вестник государственного и муниципального управления. 2013. №1. С. 53-60.

5. Зайончковский П. А. Самодержавие и русская армия на рубеже XIX-XX. 1881-1903. М.: Мысль, 1973. 351 с

6. Иванова Г. В., Юмашева Ю. Ю. Историография просопографий // Круг идей: алгоритмы и технологии исторической информатики. Труды IX конференции Ассоциации «История и компьютер». М.; Барнаул: Изд-во Алт. ун-та, 2005 С.121-152. 
7. История русской императорской армии [Электронный ресурc]. URL: http://regiment.ru/bio/L/71.htm (Дата обращеения 17.08.2019).

8. Курицын С. В. Братание 11-й армии Юго-западного фронта весной-летом 1917 г. как феномен повседневной жизни военнослужащих российской армии // История: факты и символы. 2019. №1 (18). C. 85-97. DOI: 10.24888/24104205-2019-18-1-85-97

9. Михайлов А. А., Филюк С. О. Реформы российских военно-учебных заведений в $1860-$ годы. Альтернативные проекты и итоги // Военно-исторический журнал. 2011. №6. С. 35.

10. Науэн М. С. Метод когортного анализа в социологии // Журнал социологии и социальной антропологии. 2006 №3. C. 137-144.

11. Офицеры русской императорской армии URL: http://ria1914.info/index.php (Дата обращения 15.08.2019).

12. Русская армия в Великой войне URL: http://www.grwar.ru/persons/persons (Дата обращения 15.08.2019).

13. Суряев В. Структура русского офицерского корпуса накануне Первой мировой войны // Российская история 2017. №6. C.114-128.

\section{References}

1. Blossfel'd H.-P., H'junink I. Issledovanie zhiznennyh putej $\vee$ social'nyh naukah: temy, koncepcii, metody i problem (The study of life paths in the social Sciences: themes, concepts, methods and problems) // Zhurnal sociologii i social'-noj antropologii. 2006. No.1. P. 15-45. (In Russian)

2. Voennaja literatura (MILITERA) (Military literature (MILITERA) URL: http://militera.lib.ru (Accessed: 15.08.2019). (In Russian)

3. Volkov S. V. Baza dannyh № 2: "Uchastniki Belogo dvizhenija v Rossii» (Database \# 2: "Participants of the White movement in Russia») [1995-2016]. URL:http://swolkov.org/2_baza_beloe_dvizhenie/2_baza_beloe_dvizhenie_abc-01.htm (Accessed: 08.08.2019). (In Russian)

4. Grebenkin A. N. Pravila priema v voenno-uchebnye zavedenija Rossijskoj imperii v 1863-1917 gg. (Rules of admission to military educational institutions of the Russian Empire in 1863-1917) // Vestnik gosudarstvennogo i municipal'nogo upravlenija. 2013. No. 1. P. 53-60. (In Russian)

5. Zajonchkovskij P. A. Samoderzhavie i russkaja armija na rubezhe XIX-XX. 1881-1903 (Autocracy and the Russian army at the turn of XIX-XX. 1881-1903). Moscow: Mysl', 1973. 351 p. (In Russian)

6. Ivanova G. V., Jumasheva Ju. Ju. Istoriografija prosopografij (Historiography of prosopography) // Krug idej: algoritmy i tehnologii istoricheskoj informatiki. Trudy IX konfe-rencii Associacii «Istorija i komp'juter». Moscow; Barnaul: ASU publ., 2005. P. 121-152. (In Russian)

7. Istorija russkoj imperatorskoj armii (History of the Russian Imperial army) URL: http://regiment.ru/bio/L/71.htm (Accessed:17.08.2019). (In Russian)

8. Kuricyn S. V. Bratanie 11-j armii Jugo-zapadnogo fronta vesnoj-letom $1917 \mathrm{~g}$. kak fenomen povsednevnoj zhizni voennosluzhashhih rossijskoj armii (Fraternization of the 11th army of the South-Western front in the spring-summer of 1917 as a phenomenon of everyday life of servicemen of the Russian army) // Istorija: fakty i simvoly. 2019. No. 1 (18). P. 85-97. DOI: 10.24888/2410-4205-2019-18-1-85-97 (In Russian)

9. Mihajlov A. A., Filjuk S. O. Reformy rossijskih voenno-uchebnyh zavede-nij v 1860 -e gody. Al'ternativnye proekty i itogi (Reforms of Russian military educational institutions in the 1860s. Alternative projects and outcomes) // Voenno-istoricheskij zhurnal. 2011. No. 6. P. 35. (In Russian)

10. Naujen M. S. Metod kogortnogo analiza v sociologii (The method of cohort analysis in sociology) // Zhurnal sociologii i social'noj antropologii. 2006. No.3. P. 137-144. (In Russian)

11. Oficery russkoj imperatorskoj armii (Officers of the Russian Imperial army). URL: http://ria1914.info/index.php (data obrashhenija 15.08.2019). (In Russian)

12. Russkaja armija $\vee$ Velikoj vojne (Russian army in the great war) [Jelektronnyj resurs]. URL: http://www.grwar.ru/ persons/persons (Accessed:15.08.2019). (In Russian)

13. Surjaev V. Struktura russkogo oficerskogo korpusa nakanune Pervoj mirovoj vojny (Structure of the Russian officer corps on the eve of the First world war) // Rossijskaja istorija. 2017. No. 6. P. 114-128. (In Russian)

\section{Сведения об авторе}

Канищев Владимир Валерьевич - кандидат исторических наук, доцент кафедры всеобщей и российской истории Тамбовского государственного университета имени Г. Р. Державина (Тамбов) / kanvladimir-tamb@yaendex.ru

\section{Information about the author}

Kanishhev Vladimir - PhD in History, Associate Professor, Chair of World and Russian history, Tambov State University named after G.R. Derzhavin (branch in Tambov) / kan-vladimir-tamb@yaendex.ru 